\title{
Hybrid Manufacturing and Rapid Prototyping in Metal Casting Industry: A Review
}

\author{
Hamid Abdillah, Ulikaryani \\ \{ hamid@polmanceper.ac.id ${ }^{1}$, phy.jog@gmail.com² $\}$ \\ Politeknik Manufaktur Ceper, Klaten, Indonesia ${ }^{1,2}$
}

\begin{abstract}
Metal Casting industry has a classic problem in handling the production process and quality control. Hybrid manufacturing and rapid prototyping are technological developments in the manufacturing sector that are currently attracting a lot of attention both within the industry and academics. Although there is no standard definition in hybrid manufacturing, this has become a lot of objects developed by researchers to find the influence of each combination of manufacturing processes carried out. Rapid prototyping in various cases shows the level of potential to reduce time and process in making a prototype. This paper is prepared to assess the potential and implications of hybrid manufacturing and rapid prototyping applications that are reviewed in the metal casting industry.
\end{abstract}

Keywords: metal casting industry, hybrid manufacturing, rapid prototyping, manufacturing technology.

\section{Introduction}

Metal casting is one method in producing objects by melting metal then pouring in the mold. The advantage of the casting sector is that it is able to make things that are simple and complicated with a single process. Therefore, the casting method is very often used for prototyping product development and mass production. Nearly $90 \%$ of all goods produced in the manufacturing sector are carried out through a metal casting process [1].

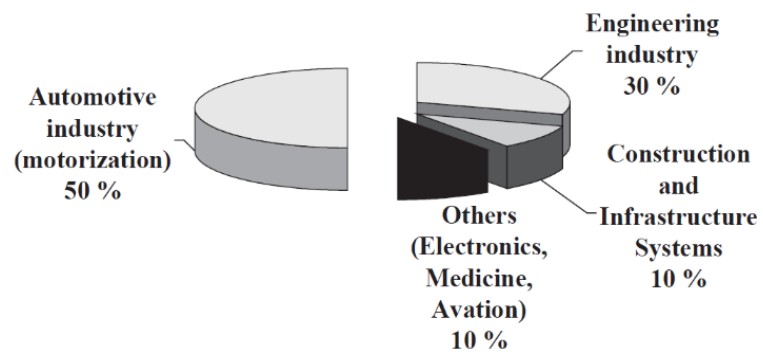

Fig. 1. Markets of foundry industry [2]

Based on the 45th Census of World Casting Production [3] stated that the metal casting sector has a large contribution to the economic growth of several large countries. Production growth in the world casting industry increased $13.7 \%$ from 2009 to 2010. However, in the 50th Census of World Casting production [4], the growth of the world metal casting industry 
tended to stagnate in the last 3 years. The growth of the metal casting industry in 2015 was only $0.4 \%$ and in 2014 only $2.37 \%$.

Globalization, innovation and the need to continue to develop and increase the effectiveness of production become a separate challenge for the metal casting sector in the industrial era 4.0. The casting industry has a strong role in manufacturing and economic growth, but must also be supported by strengthening technology to face other competitors [5]. The metal casting sector must also be able to meet the expectations of customers in quality assurance, production time cuts and competitive prices [6].

Absolute innovation to be done in the face of the industrial era 4.0. Competition in the 4.0 industry era is currently not determined by the size of a company but is determined by new innovative ideas that give more value and solve problems for consumers. Business innovation that can be done on business, production and service models [7]. In the foundry industry, the innovation that can be done is innovation in the production process. With the innovation of the production process, companies can cut and streamline the production process by using new production technologies that develop in the industrial era 4.0

The above explanation addresses the urgency of innovation and a touch of new technology for the production process, increasing the growth and competitiveness of the very high metal casting industry. This paper was prepared to study rapid prototyping and hybrid manufacturing technology to answer the opportunities and challenges for the metal casting industry in the 21 st century.

\section{Method}

The method used in this paper is the literature review. Sources of data are obtained from primary literature such as journals and proceedings, besides that, it's are also used as a literature of books from scientific books and articles. The data used is a prevalent research and theory with the application of hybrid manufacturing and rapid prototyping in the metal casting industry. Data analysis was carried out through an in-depth discussion to examine the development and advanced research frameworks that could be carried out in the process of defusion of hybrid technology manufacturing and rapid prototyping.

\section{Result And Discussion}

Based on the literature review, the description of hybrid manufacturing and rapid prototyping in its application in the metal casting industry is divided into several parts, namely (1) the description of the strategy and challenges of the metal casting industry in the industrial revolution; (2) the description of the concept of hybrid manufacturing; (3) the elaboration of the results of the application study and the opportunity for developing hybrid manufactures in the metal casting industry; (4) the description of the concept of rapid prototyping; (5) the elaboration of the results of the application study and the opportunity for the development of rapid prototyping in the metal casting industry. 


\subsection{Strategy And Challengge in Metal Casting Industry}

The industrial revolution is a process of rapid change in the development of industry in order to improve the quality and quantity of industrial products or production. History records that the world has experienced three industrial revolutions and is currently facing a fourth industrial revolution marked by the emergence of supercomputers, smart robots, artificial intelligence, vehicles without drivers, genetic editing and the development of neurotechnology that enables humans to further optimize brain function.

The metal casting sector as one of the manufacturing industries that is widely used to produce engine components must, of course, follow a strategy to be able to face the challenges of development and revolution of the times. several strategies that can be pursued by the metal casting sector to face the industry 4.0 challenges in the 21 st century are: (1) developing technology and adding the use of other technologies to support productivity, (2) job management, especially complex work, (3) strengthening cooperative relationship, (4) reduce production costs, (5) hold sustainable R \& D [8].

The use of technology to support productivity, management of complex jobs and reducing production costs are the main problems in the metal casting sector. This is due to the long production process. Metal casting production process generally consists of: (1) making patterns and mold, (2) melting, (3) pouring (4) finishing [9]. A pattern is a replica of the object to be cast. The pattern is a reference in the mold making process. Melting is the process of making metal liquids which will be poured into molds, while finishing is a cleaning process and final workings of castings (usually using machining processes) after pouring. Therefore, there needs to be a continuous $\mathrm{R} \& \mathrm{D}$ to be able to improve the production process in the foundry industry.

$\mathrm{R} \& \mathrm{D}$ in the academic and industrial realm is important to answer the challenges of the industrial revolution, especially in the metal casting sector. R \& D directions for the metal casting industry sector that can help and respond to challenges in the face of industry 4.0 revolution are as follows: (1) new technology development and alloy casting, (2) melting and metal liquid preparation, ( 3 ) molds and core manufacturing processes, (4) new production systems and quality control, (5) technology for efficient use of energy and materials [2].

The issue regarding the system and production process as well as quality control in the manufacturing industry, especially metal casting, is an issue that continues to evolve and develop. Hybrid manufacturing and rapid prototyping that are a trend in the manufacturing industry can certainly contribute to the R \& $\mathrm{D}$ system and production processes in the metal casting sector. We will further discuss the basic concepts of hybrid manufacturing and rapid prototyping and their opportunities and applications in the metal casting sector and their impact on quality control.

\subsection{Hybrid Manufacturing}

Hybrid manufacturing is a manufacturing technology that was developed by combining two or more manufacturing methods. At present, hybrid manufacturing is becoming an interest for industry and academics in manufacturing. this is due to the potential of these technologies which can provide opportunities to produce special components which initially lack good economic value [10]. This is caused by, the need for hybrid manufacturing, in general, is driven by; (1) every manufacturing method has advantages and disadvantages, (2) some industrial products cannot be produced with one type of manufacturing method. So that the 
product production process is superior in terms of time, capability and cost if it is produced with hybrid manufacturing.

In general, manufacturing methods can be divided into 5 types, namely additive, transformative, subtractive, joining and dividing manufacturing [11].

1. Additive manufacturing is a man-manufacturing process that is carried out by adding material to the workpiece that is carried out until the desired workpiece is obtained so that the mass after work is greater than the previous mass. Examples of additive manufacturers are rapid prototyping, die casting, injection molding etc.

2. Transformative manufacturing is a manufacturing process that is carried out by means of changing the basic shape of the workpiece into a desired form so that no mass changes. An example of transformative manufacturing is forming and heat treatment.

3. Subtractive manufacturing is a process of manufacturing workpieces that is done by reducing or cutting the material that is processed until it reaches the desired shape. An example of subtractive manufacturing is the machining process such as turning, milling, EDM, water jet, etc.

4. Joining manufacturing is a process of manufacturing a workpiece that is done by connecting two or more objects to form the desired workpiece. An example of joining manufacturing is welding and assembly.

5. Dividing manufacturing is a manufacturing process that is opposite to joining. An example in dividing manufacturers is sawing and dis-assembly.

One example of hybrid manufacturing that is currently developing is a combination of CNC and 3D printers [12]. The concept of hybrid manufacturing aims to increase efficiency and improve the shortcomings of each manufacturing process. Subtractive manufacture with $\mathrm{CNC}$ has several limitations in the form of material losses that are lost due to the cutting process. Whereas additive manufacturers using 3D printing has the disadvantages of surface smoothness and product accuracy [13].

\subsection{Hybrid Manufacturing in Metal Casting Industry}

Hybrid manufacturing in the foundry industry can provide influence to increase productivity and quality control. When viewed from each process carried out in metal casting, in fact in a metal casting process has used hybrid manufacturing. As in the pattern making process, generally cast patterns are made with dividing wood materials, then joining between parts and diffusing with putty and sanding (subtractive) processes. The process consists of at least 3 types of manufacturing processes. The whole process is carried out to obtain a pattern that matches its shape and geometry and has a smooth surface so as to facilitate the making of a cavity in the sand mold [14].

In the process of casting non-ferrous metals such as aluminum casting, after the cooling process of casting objects an advanced process is carried out in the form of heat treatment. This heat treatment process aims to obtain the microstructure and mechanical strength of a material in accordance with applicable standards [15]. In the casting process, the quality of a cast object is not only determined by the composition of the ingredients and melting. However, the quality of the material cast is also viewed from the microstructure and mechanical strength of the object. So that to get good cast quality, a heat treatment process must be carried out to meet the standard material properties and microstructure of the intended material. This also applies to the ferrous metal casting process [16]. 
Hybrid manufacturing in the foundry industry can provide influence to increase productivity. Rapid prototyping and CNC can be used to produce complex patterns in a short time [17]. In addition, by using rapid prototyping and CNC methods also opens a great opportunity in realizing casting work that has a high level of precision. efforts to shorten the time, reduce the manufacturing process chain and reduce production costs, research focuses on the integration of several manufacturing processes into one machine [18]. Integrated or hybrid systems have all the same features and advantages as rapid prototyping systems, plus a new set of features and benefits.

When viewed in terms of quality control, hybrid manufacturing can act as an effort to increase the quality of product output, especially in achieving product standards. Each cast material certainly has its own mechanical and microstructure standards, and this cannot be achieved in one work process.

\subsection{Rapid Prototyping}

Today's industrial demands are always related to speed, efficiency, and productivity. Prototyping is a general term used today to describe the shape, size, and performance of a product design. The prototype making is generally done exactly the same as the manufacture of a product, so it takes a lot of time and money.

In the aspect of production, rapid prototyping is called a powerful technology to face global challenges. Rapid prototyping technology has now begun to be widely used in the automotive, aerospace, health and other production products [19]

Rapid Prototyping is a number of techniques used to quickly manufacture a model of a component or assembly that uses computer-aided design (CAD) three-dimensional (3D) data [20]. 3D CAD data is then processed using technologies such as:

1. Photo masking or solid ground curing technique

2. Selective Laser Sintering (SLS)

3. Fused Deposition Modeling (FDM)

4. Laminated Object Manufacturing (LOM)

5. 3D Printer

6. Thermo Jet Process

7. Contour crafting

Rapid prototyping is intended to facilitate and cut time in making prototypes from a product, increasing the effectiveness of product design communication, increasing the number of variants and the level of product effectiveness. In addition, it can also provide convenience in manufacturing processes and manufacturing aids [21].

Rapid prototyping process consists of 2 types, namely: (1) rapid prototyping additive, (2) subtractive rapid prototyping [22]. Additive rapid prototyping is a prototyping process that is carried out by adding material to the formation of the desired object/ component/prototype. This type of additive has the advantage of (1) not having design limitations, (2) using the more optimum material so as to save production costs, (3) compact workmanship for manual mechanism components. 


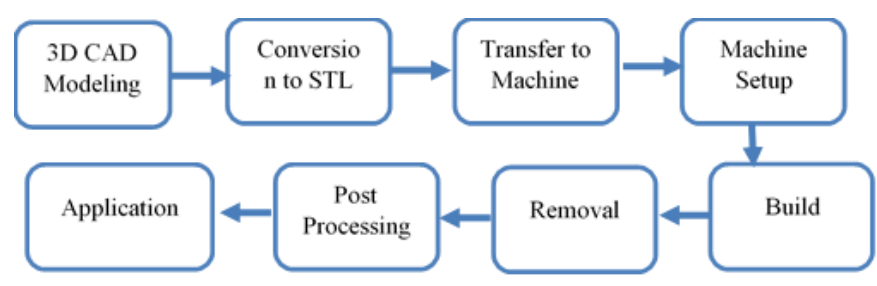

Fig. 2: Steps for operating Additive Rapid Prototyping. [23]

Subtractive rapid prototyping is a rapid prototyping process which is done by cutting / cutting material to obtain the form of the pattern, / the required compote/prototype. The subtractive type has the advantages of (1) good dimensional accuracy, (2) good surface smoothness, (3) structural integrity of material, and (4) suitability for large workspieces.

\subsection{Rapid Prototyping in Metal Casting Industry}

Rapid prototyping, when applied in metal casting sectors, has the potential to increase productivity and quality of patterns. The working time of a metal casting is dominated by preparation of patterns and molds. Patterns making takes up almost $70 \%$ of production time [24].

In the manufacturing process, the cast pattern is still dominated by conventional work with wood or resin raw materials. Processing time for making this pattern depends on the level of complexity of the object to be cast. The more complicated the shape and size of the object that will be made is the determining factor in the duration of making cast patterns. Therefore the manufacture and quality of castings become an important key in the casting process. This is because pattern making is the first step in the casting process and patterns with accurate surface quality and dimensions will minimize cast defects [25].

Rapid prototyping on gypsum molds provides high flexibility and is capable of large elastic deformations in complex models [26]. Rapid prototyping is carried out using the combustion of powder requires hardening of printed models by soaking them. The results of this experiment show that the resulting model has a smooth surface and does not show cast defects.

Another implementation of rapid prototyping is the core model manufacturing process of a flying machine blade. The result of this experiment is that rapid prototyping has advantages in its use for precision checking processes [27].

From the explanation, show the potential and advantages of rapid prototyping in the field of metal casting. Rapid Prototyping has the ability to increase quality, flexibility and reduce production time on casting patterns making. However, in Indonesia, there has not been much research and application of technology, especially in the perspective of the state of the medium and micro industries in Indonesia.

\section{Conclusion}

The conclusion of this review is the use of hybrid manufacturing and rapid prototyping can have a positive impact on the metal casting industry. These benefits are viewed from the potential and implications of implementing hybrid manufacturing and rapid prototyping in systems and production processes and quality control. This opens up opportunities for further 
research and development for related universities/polytechnics/academics that examine more deeply the impact of implementing hybrid manufacturing and rapid prototyping in the casting industry. So that harmony will result in increasing the capability of the metal casting industry and diffusion technology in the industry.

Acknowledgment. This work is realized in the 2018 research and community service grant from the Ministry of Research, Technology and Higher Education. According to the Decree No. 116 / K6 / KM / SP2H / PENELITIAN / 2018 The purpose of this activity is to increase the capacity of young lecturers in terms of research and publication

\section{References}

[1] A. Lupulescu, S. Henry, K. Marken et al., "Science of Casting and Solidification: ASM Handbook Contributions-Honoring Professor Doru Michael Stefanescu," Advances in the Science and Engineering of Casting Solidification, pp. 3-8: Springer, 2015.

[2] M. Holtzer, R. Dańko, and S. Żymankowska-Kumon, "Foundry industry-current state and future development," Metalurgija, vol. 51, no. 3, pp. 337-340, 2012.

[3] 45th Census of World Casting Production, vol. 12, 2011.

[4] 50th Census of World Casting Production, vol. 16, 2016.

[5] S. Dalquist, and T. Gutowski, "Life cycle analysis of conventional manufacturing techniques: sand casting." pp. 631-641.

[6] B. Ravi, "Computer-aided casting design-past, present and future," Korea, vol. 1, no. 1.48, pp. 777, 1999.

[7] M. Rüßmann, M. Lorenz, P. Gerbert et al., "Industry 4.0: The future of productivity and growth in manufacturing industries," Boston Consulting Group, vol. 9, 2015.

[8] M. Chang, "Foundry future: challenges in the 21st century." pp. 18-23.

[9] C. Kenji, and T. Surdia, “Teknik Pengecoran Logam,” Pradya Paramita, Jakarta, 1996.

[10] Z. Zhu, V. G. Dhokia, A. Nassehi et al., "A review of hybrid manufacturing processes-state of the art and future perspectives," International Journal of Computer Integrated Manufacturing, vol. 26, no. 7, pp. 596-615, 2013.

[11] A. Nassehi, S. Newman, V. Dhokia et al., "Using formal methods to model hybrid manufacturing processes," Enabling Manufacturing Competitiveness and Economic Sustainability, pp. 52-56: Springer, 2012.

[12] M. Müller, and E. Wings, "An Architecture for Hybrid Manufacturing Combining 3D Printing and CNC Machining," International Journal of Manufacturing Engineering, vol. 2016, 2016.

[13] K. Boivie, R. Karlsen, and P. Ystgaard, "The concept of hybrid manufacturing for high performance parts," South African Journal of Industrial Engineering, vol. 23, no. 2, pp. 106-115, 2012.

[14] S. Hurst, Metal casting: Appropriate technology in the small foundry: Intermediate Technology Publications London, 1996.

[15] J. Brown, Foseco non-ferrous foundryman's handbook: Butterworth-Heinemann, 1999.

[16] J. Brown, "Foseco Ferrous Foundryman's Handbook," Butterworth-Heinemann, 2000.

[17] G. Redden, "Cast tooling with rapid prototype patterns," Rapid Prototyping Casebook, pp. 115, 2001.

[18] J. K. Nagel, and F. W. Liou, "Hybrid manufacturing system modeling and development." pp. 189-198.

[19] M. A. Boboulos, CAD-CAM \& rapid prototyping application evaluation: Bookboon, 2010.

[20] E. K. Varma, S. Madhukar, B. Akhil et al., "Future of manufacturing technology rapid prototyping technique," International Journal of Mechanical Engineering \& Technology (IJMET), vol. 7, no. 5, pp. 117-126, 2016.

[21] T. Grimm, User's guide to rapid prototyping: Society of Manufacturing Engineers, 2004.

[22] D. Bryden, CAD and rapid prototyping for product design: Laurence King Publ., 2014. 
[23] I. Gibson, D. W. Rosen, and B. Stucker, "Design for additive manufacturing," Additive Manufacturing Technologies, pp. 299-332: Springer, 2010.

[24] D. Pal, and B. Ravi, "Rapid tooling route selection and evaluation for sand and investment casting," Virtual and Physical Prototyping, vol. 2, no. 4, pp. 197-207, 2007.

[25] S. Lampman, "Casting design and performance," ASM International, 2009.

[26] K. Wańczyk, A. Gil, and P. Kowalski, "The Use of Rapid Prototyping Methods to Perform Flexible Pattern Mold for Compressor Turbine Casting in the Gypsum Molds," Archives of Foundry Engineering, vol. 15, 2015

[27] P. Rokicki, G. Budzik, K. Kubiak et al., "Rapid prototyping in manufacturing of core models of aircraft engine blades," Aircraft Engineering and Aerospace Technology: An International Journal, vol. 86, no. 4, pp. 323-327, 2014. 